\title{
Accelerated evolution of the mitochondrial genome in an alloplasmic line of durum wheat
}

Andrzej K Noyszewski ${ }^{1 \dagger}$, Farhad Ghavami ${ }^{2+}$, Loai M Alnemer ${ }^{3}$, Ali Soltani ${ }^{1}$, Yong Q Gu ${ }^{4}$, Naxin Huo ${ }^{4}$, Steven Meinhardt ${ }^{5}$, Penny MA Kianian ${ }^{1}$ and Shahryar F Kianian ${ }^{6^{*}}$

\begin{abstract}
Background: Wheat is an excellent plant species for nuclear mitochondrial interaction studies due to availability of large collection of alloplasmic lines. These lines exhibit different vegetative and physiological properties than their parents. To investigate the level of sequence changes introduced into the mitochondrial genome under the alloplasmic condition, three mitochondrial genomes of the Triticum-Aegilops species were sequenced: 1) durum alloplasmic line with the Ae. Iongissima cytoplasm that carries the T. turgidum nucleus designated as (lo) durum, 2) the cytoplasmic donor line, and 3) the nuclear donor line.

Results: The mitochondrial genome of the T. turgidum was 451,678 bp in length with high structural and nucleotide identity to the previously characterized $T$. aestivum genome. The assembled mitochondrial genome of the (lo) durum and the Ae. longissima were 431,959 bp and 399,005 bp in size, respectively. The high sequence coverage for all three genomes allowed analysis of heteroplasmy within each genome. The mitochondrial genome structure in the alloplasmic line was genetically distant from both maternal and paternal genomes. The alloplasmic durum and the Ae. longissima carry the same versions of atp6, nad6, rps19-p, cob and cox2 exon 2 which are different from the T. turgidum parent. Evidence of paternal leakage was also observed by analyzing nad 9 and orf359 among all three lines. Nucleotide search identified a number of open reading frames, of which 27 were specific to the (lo) durum line.

Conclusions: Several heteroplasmic regions were observed within genes and intergenic regions of the mitochondrial genomes of all three lines. The number of rearrangements and nucleotide changes in the mitochondrial genome of the alloplasmic line that have occurred in less than half a century was significant considering the high sequence conservation between the T. turgidum and the $T$. aestivum that diverged from each other 10,000 years ago. We showed that the changes in genes were not limited to paternal leakage but were sufficiently significant to suggest that other mechanisms, such as recombination and mutation, were responsible. The newly formed ORFs, differences in gene sequences and copy numbers, heteroplasmy, and substoichiometric changes show the potential of the alloplasmic condition to accelerate evolution towards forming new mitochondrial genomes.
\end{abstract}

Keywords: Aegilops Iongissima, Triticum turgidum, Heteroplasmy, Paternal leakage, atp6, Next generation sequencing, Cytoplasmic male sterility, Alloplasmic line

\footnotetext{
* Correspondence: Shahryar.Kianian@ars.usda.gov

${ }^{\dagger}$ Equal contributors

${ }^{6}$ Cereal Disease Laboratory, USDA-ARS, Minneapolis, MN 55108, USA

Full list of author information is available at the end of the article
} 


\section{Background}

Mitochondria are a crucial component of every eukaryotic cell and provide indispensable functions including i) cell energy supply ii) synthesis of essential molecules such as phospholipids and heme, and iii) mediating multiple cellular signaling pathways including stress response, apoptosis and aging [1,2]. It is widely accepted that mitochondria and chloroplast descended from free-living bacterial ancestors [3] that were acquisitioned into eukaryotic cells. Following their acquisition, most of the genes in these organelles were either lost or transferred to the nucleus [3]. Although these organelles possess their own genomes, most of their proteins (93-99\%) are encoded in the nucleus, synthesized in the cytoplasm and then imported for use [4].

There is great variability in size and number of genes of eukaryotic mitochondrial genomes. The average size of a mitochondrial genome is about $15-60 \mathrm{~kb}$ in animals while in seed plants they range from 222 to $2,900 \mathrm{~kb}$ $[5,6]$. The number of genes in the mitochondrial genome of eukaryotes is also variable, from 5 in plasmodium to 100 in jakobid flagellates and with average between 40 and 50 [6]. Recent sequencing of the hexaploid wheat (T. aestivum cv. Chinese Spring) mitochondrial genome revealed interesting features of this genome relative to other monocots such as rice and maize [7]. The size of this genome is $452 \mathrm{~kb}$ [7] compared to $491 \mathrm{~kb}$ for rice [8], and 536 to $740 \mathrm{~kb}$ for various Zea mays genotypes [9]. This mitochondrial genome of hexaploid wheat includes 55 known genes and 179 ORFs larger than 300 bp in size. About $15 \%$ of this genome is repetitive sequences, $3 \%$ is of chloroplast origin and $0.2 \%$ is of retro-element origin. The gene order of the wheat mitochondrial genome showed little synteny to that of rice and maize [7].

A diverse range of methods have been used for sequencing the whole mitochondrial genome of over fifty different species currently deposited at NCBI Organelle Genome Resources. At the beginning BAC library construction combined with Sanger sequencing was the only method for mitochondrial DNA (mtDNA) sequencing [7,10-12], although currently next generation sequencing (NGS) is being used as a replacement [13-15]. The advent of NGS techniques (such as Roche/454 GS-FLX and Illumina Hiseq) set the stage for high throughput, inexpensive mitochondrial genome comparisons among diverse species [13]. However, the multipartite nature along with large and short repeated sequences [16] has made de novo assembly of the mitochondrial genome a challenge. Despite the challenges in de novo assembly the depth of sequencing provided by NGS is so high that is quite suitable for detection of mitochondrial genome variants in a cell [17].

Usually more than one type of mitochondrial genome (mitotype) occurs in a cell, defined as heteroplasmy. The ratio of different mitotypes in a heteroplasmic population may be variable, with one major mitotype dominant and others present in a very low proportion $[18,19]$. Heteroplasmy seems to be an evolutionary strategy of maternally inherited plant mitochondrial genomes to compensate for lack of sexual recombination. Therefore different mitotypes in the cell accumulate as a reservoir of genetic variability and may undergo accelerated evolution [20]. Occasionally, some mitotypes are selected and amplified in the process called substoichiometric shifting, and become the prominent mitochondrial genome [20]. Prevalence of each mitotype is believed to be controlled strictly by nuclear gene(s) in a tissue specific manner [21]. An example of this interaction is the nuclear Fertility restorer $(F r)$ gene in common bean which decreases the male sterility associated mitotype ( $p v s)$ to a substoichiometric level that recovers the fertility [21]. A detailed study on the complex nature of the plant mitochondrial genome was conducted by analyzing the composition of three different genes, atp4, atp6 and rps7, in alloplasmic and euplasmic lines of wheat [22]. This study suggested that paternal mitochondrial types are increased by up to $30 \%$ in alloplasmic lines but they tend to be silenced.

Alloplasmic lines are created when the cytoplasm of one species is replaced by that of another species through substitution backcrossing. This alloplasmic condition disrupts the interactions between the nucleus and cytoplasm which have co-evolved together as illustrated in alloplasmic lines of Tigriopus and Drosophila [23]. The disruption of nuclear mitochondrial (NM) interactions in plants by alloplasmic condition usually leads to cytoplasmic male sterility (CMS) $[24,25]$. It is believed that pollen-forming tissue demand tremendous amount of energy and have a lower threshold for respiratory deficiencies than other plant tissue $[26,27]$. Therefore in most cases the alloplasmic lines are CMS as well. In all cases examined, the CMS phenotype results from the presence of novel proteins in the mitochondria affecting mitochondrial function and pollen development $[4,28]$. The new ORFs, leading to the production of novel proteins, are the consequence of highly rearranged mitochondrial genome [9]. Research also indicates alterations in the mitochondrial gene expression patterns in alloplasmic plants $[29,30]$.

Wheat has the largest collection of alloplasmic lines created in any species [31,32], providing an un-precedent opportunity to analyze NM interactions. These lines have exhibited vegetative and physiological phenotypes different from their parents. Some alloplasmic wheat, with the Ae. mutica or the Ae. crassa cytoplasms, showed higher yield, increased tolerance to abiotic stresses, and improved seed quality [32-34]. In this study, the mitochondrial genomes of three Triticum-Aegilops species were sequenced and described; durum alloplasmic line (lo) durum with the 
Ae. longissima cytoplasm with the nucleus from the T. turgidum var. durum plus its two euplasmic parents. The (lo) durum line was developed and described by S.S. Maan [32]. The main focus of this study was to investigate the level of changes that occurred in the mitochondrial genome in the alloplasmic condition. Sequencing of mitochondrial genome in these three lines allows for analysis of changes in the mitochondrial genome of the alloplasmic line compared to its euplasmic parents.

\section{Results}

\section{Genome assembly}

The average sequence read length was 449 bp as expected for 454 GS FLX sequencing technology. The purification method [35] provided mitochondrial DNA free from nuclear DNA contamination which was confirmed by quantitative real time PCR. Based on sequencing read counts, 3 to $9 \%$ of overall reads were chloroplastic DNA and no nuclear DNA was detected. The majority of sequencing reads (66-79\% of total reads) were used for mitochondrial genome assembly, with the exception of the Ae. longissima where only $32 \%$ of the reads were used. The remaining $12-28 \%$ of reads that were not assembled created additional contigs which contained valid mitochondrial sequences. These contigs may provide additional information about possible mitotypes present in smaller proportion relative to the most prevailing type presented in the final assemblies.

The mitochondrial genomes obtained for T. turgidum was $451,678 \mathrm{bp}$ and sequence was similar to the previously sequenced T. aestivum cv. Chinese Spring [7]. Although sequences were nearly identical, 40 single nucleotide polymorphisms (SNPs) were observed between the two genomes, five were in known mitochondrial genes: rps1, rps2, cox3 and $c c m F N$. The estimated size of the (lo) durum and the Ae. longissima genomes were 431,959 bp and 399,005 bp, respectively. Overall coverage of the sequenced genomes was 61 - 133x (Table 1), which allowed analysis of heteroplasmy.

\section{Genome structure}

Using the $T$. aestivum $\mathrm{cv}$. Chinese Spring as the reference, the T. turgidum, the (lo) durum, and the Ae. longissima mitochondrial genomes were assembled. The

Table 1 Final assembly results for mitochondrial genomes of various Triticum/Aegilops species

\begin{tabular}{lcccc}
\hline Species & Coverage (x) & $\begin{array}{c}\text { Genome } \\
\text { size (bp) }\end{array}$ & $\begin{array}{c}\text { Ave. read } \\
\text { length (bp) }\end{array}$ & $\begin{array}{c}\text { \# of } \\
\text { contigs }\end{array}$ \\
\hline T. turgidum & 114 & 451,678 & 450 & 1 \\
Ae. longissima & 61 & 399,005 & 442 & 2 \\
(lo) durum & 133 & 431,959 & 436 & 1 \\
\hline
\end{tabular}

T. turgidum mitochondrial genome sequence is missing a region of about 1,200 bp (corresponding to 179,037 to 180,129 bp position) present in the $T$. aestivum mitochondrial genome (Figure 1). There were 12 and 13 regions with no reads for the Ae. longissima and the (lo) durum, respectively (Figure 1). However, nine of these regions (regions I, II, V, VII, VIII, IX, XII, XIII, XIV and $\mathrm{XV}$ ) appeared to be in common, but there are size differences between some of them (especially at regions $\mathrm{I}, \mathrm{V}$ and IX). Regions VI, X, XI and XVI were present in the Ae. longissima but not in the alloplasmic line. Regions III, IV, and VII were present in the alloplasmic line but not the Ae. longissima (Figure 1). These differences could indicate the presence of genome rearrangements, new genetic information or high polymorphism hindering complete assembly. These results indicate changes in the predominant genome and also the lack of these regions in the minor mitotypes.

Considering the gaps in the reference assembly, de novo assembly of the genomes could reveal structural changes reflecting recombination and/or other rearrangement events within the mitochondrial genomes. Within these regions are blocks of DNA that share high sequence similarity (about 99\%), indicating conservation of mitochondrial genome content, but not genome structure. To precisely describe the possible recombination events within genomes and the differences which appear in the (lo) durum line as an effect of the alloplasmic condition, a detailed gene order description was initiated. Based on the syntenic relationship between genomes (Figure 2), three gene categories were established. 1 ) genes, which do not follow any recognizable pattern, 2) gene pairs that move together and, 3) genes that tend to remain together in blocks. Examination of these blocks revealed that there were 19 recombination/rearrangement events between the $T$. turgidum and the alloplasmic (lo) durum and 13 between the Ae. longissima and the alloplasmic (lo) durum. Four pairs of genes (labeled a, b, c and d) and seven conserved gene blocks can be detected between the alloplasmic line and both parents (Figure 2). These blocks account for 44 genes (or gene exons) out of 61 total, providing evidence for the relative stability of the gene order between these species. Three gene blocks show rearrangements within them: blocks I, V and VI, with lengths of 28,642 bp, 20,955 bp and 22,939 bp in the T. turgidum (Figure 2). Blocks I and V conserve the same gene order except for atp4 (Block I) and cob (Block V) having moved from one end of the block to the other end. In block VI, orf359 located after ccmFC exon-2 in the T. turgidum and nad5 exons 3 and 4 are reversed relative to (lo) durum. The location of rps7 has been moved adjacent to block VI in the Ae. longissima and (lo) durum. The gene blocks consist of about $32 \%(143,445 \mathrm{bp})$ of the whole genome. 
Triticum turgidum

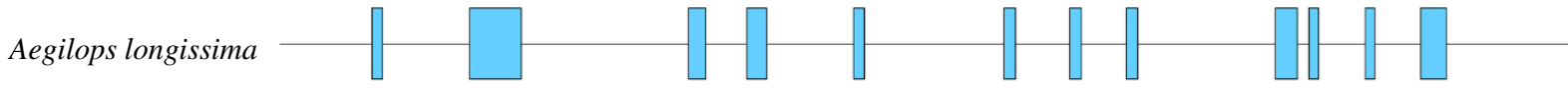

(lo) durum

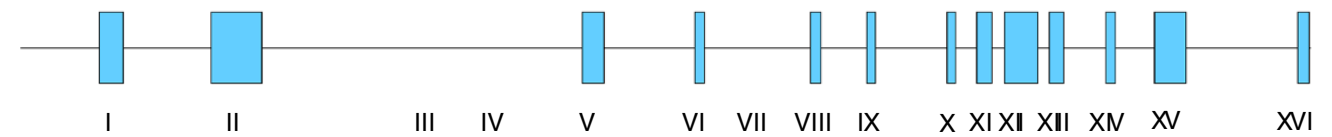

$0 \mathrm{bp}$

$452,000 \mathrm{bp}$

Figure 1 Comparison of mitochondrial genomes in the alloplasmic lines and its parental lines based on reference assembly. Blue boxes represent gaps (>3,000 bp) in assembly as compared with the Triticum aestivum (NC_007579.1) reference. The T. turgidum assembly has only one gap of 1,200 bp that is not indicated.

\section{Major differences in genes}

The 39 protein coding genes, three rRNA and 17 tRNA genes characterized in the $T$. aestivum mitochondrial genome [7] were identified in the sequenced lines. Majority of the genes are highly conserved between mitochondrial genomes in these three lines (Additional file 1: Table S1).

Six genes (atp6-1, rps19-p, nad9, nad6, cob and cox2 exon 2) had many nucleotide changes in the (lo) durum and the Ae. longissima genomes compared with the $T$. turgidum genome. One difference is recognized in the atp6 gene between the T. turgidum (1161 bp) and the (lo) durum line (1248 bp). This mitochondrial gene, encodes ATP synthase F0 subunit 6. The apt6-1 gene found in the Ae. longissima and the (lo) durum (designates as atp6-L) has an altered pre-sequence in comparison to the T. turgidum (designated as apt6-T). However, there was no difference in the surrounding region of this gene which is conserved among all three species. In addition, they share a highly similar core region of 869 bp (Additional file 2: Figure S1). A BLAST search found the pre-sequence of atp 6 from the Ae. longissima and the (lo) durum is present only in the male sterile alloplasmic $T$. aestivum line with the Ae. kotschyi cytoplasm reported recently [36]. In addition to having the characteristic pre-sequence for the female parent, the (lo) durum has a number of SNP's in the core region when compared to the T. turgidum gene. These changes are $\mathrm{C} / \mathrm{A}^{520}, \mathrm{~A} / \mathrm{T}^{543}, \mathrm{~T} / \mathrm{A}^{544}, \mathrm{~A} / \mathrm{T}^{580}, \mathrm{~T} / \mathrm{A}^{581}, \mathrm{~A} / \mathrm{C}^{595}$, $\mathrm{T} / \mathrm{G}^{639}$, including SNP $\mathrm{T} / \mathrm{G}^{560}$ specific only to the (lo) durum. The amplification of atp6-L and atp6-T alleles based on mitochondrial DNA and total DNA isolation was performed to confirm the sequences obtained from the assembly (Figure 3). The atp6-T amplification was detected in the T. turgidum mtDNA, but not in the Ae. longissima and the (lo) durum mtDNA. When PCR was performed based on the total DNA, no product was observed in the case of the Ae. longissima, but for the (lo) durum, and the T. turgidum a proper allele was amplified. Amplification of atp6-L allele (mitochondria DNA only) confirmed its presence in the Ae. longissima and the (lo) durum. The T. turgidum showed no proper amplification in mtDNA; however, the allele seems to be present in its nucleus due to amplification in total DNA.

Another major gene difference was observed in nad9 (Additional file 4: Figure S2). A four-nucleotide deletion (TGTG ${ }^{134-137}$ ) was present in nad9 of the Ae. longissima. The alloplasmic durum line doesn't share this deletion. However, a characteristic di-nucleotide difference, $\mathrm{TG} / \mathrm{CA}^{134-135}$ in relation to the $T$. turgidum, was observed resulting in $\mathrm{V} / \mathrm{A}^{45}$ substitution in the nad9 protein. The four-nucleotide deletion found at position 135 creates a frame shift in the Ae. longissima gene and generates a STOP codon at position $158\left(\mathrm{TAG}^{158-160}\right)$. This creates an alteration in protein length compared to the T. turgidum. Beside these changes, an additional three SNPs were observed in the region before the STOP codon, but no other polymorphisms were found across the rest of the gene. There is a SNP $\mathrm{A} / \mathrm{C}^{118}$ specific to (lo) durum, and two SNPs C/ $\mathrm{A}^{122}$ and $\mathrm{A} / \mathrm{T}^{125}$ found in both the Ae. longissima and (lo) durum. Each of the SNPs creates amino-acid changes, $\mathrm{N} / \mathrm{H}^{40}, \mathrm{~S} / \mathrm{Y}^{41}, \mathrm{~K} / \mathrm{I}^{42}$ respectively, in the nad 9 protein.

The nad6 mitochondrial gene is responsible for coding subunit 6 of Complex I, the NADH-ubiquinone oxidoreductase, which is built from at least 30 different subunits that are mainly encoded by the nucleus. Multi-alignment of the nad6 gene alleles (Additional file 5: Figure S3) shows that a truncated version of nad6 is present in the Ae. longissima and the (lo) durum lines, but not in the $T$. turgidum. The conserved region begins at the ATG start codon and continues until nucleotide 703. No 


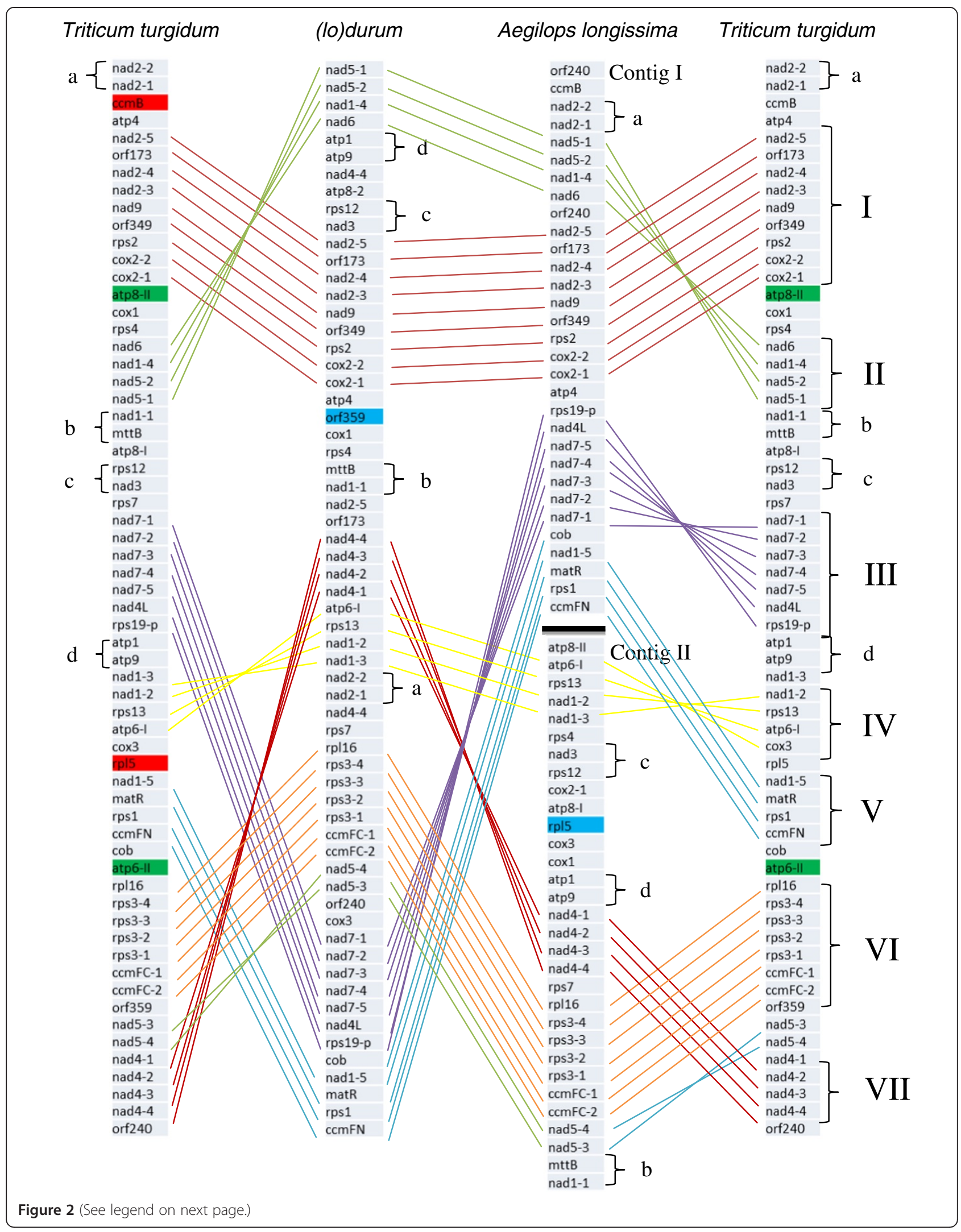


(See figure on previous page.)

Figure 2 Graphical representation of the synteny observed in the Triticum turgidum, the (lo) durum and the Aegilops longissima mitochondrial genomes based on gene localization. Pairs of genes found together in all lines a, b, c, d and gene blocks ( $-\mathrm{VII})$ are shown. Black line in the Ae. longissima indicates the position of border between the two contigs that could not be merged by de novo assembly. Genes labeled as green are present only in one copy in the (lo) durum and the Ae. longissima, blue are missing from either the Ae. longissima or the (lo) durum and gene labeled in red are not present in our final assembly of the (lo) durum line.

polymorphism was found between the alloplasmic line and its parents within the conserved region of the gene.

A nine-nucleotide deletion (AAAGGTTGG ${ }^{122-130}$ ) in the rps19-p pseudo gene was recognized in the T. turgidum mitochondrial in relation to the (lo) durum and the Ae. longissima. There are no allelic differences between the last two lines (Additional file 6: Figure S4). A polymorphism was also identified in the sequence of $c o b$ and cox 2 exon- 2 when the T. turgidum was compared to the (lo) durum and the Ae. longissima. Both genes were $10 \mathrm{bp}$ shorter at the 3 'end in the T. turgidum compared to the other two lines (data not shown).

Polymorphism of genes within and between chondriomes There were multiple alleles of a gene present at different stoichiometric levels due to heteroplasmy in chondriome of each line. To identify nucleotide changes in the genes between chondriomes, the predominant allele for each line was used for comparison. In total 10 and 14 SNPs were identified for the Ae. longissima and the alloplasmic line compared to the $T$. turgidum, respectively
(Tables 2 and 3). The total number of nucleotide variations observed in the alloplasmic (lo) durum line was higher than any of the other species examined. Six SNPs found in cox3 exon-2 $\left(\mathrm{GA} / \mathrm{TC}^{687}\right), \mathrm{mttB}\left(\mathrm{T} / \mathrm{G}^{41}\right), r p s 2$ $\left(\mathrm{A} / \mathrm{T}^{233}\right)$, rps4 $\left(\mathrm{C} / \mathrm{A}^{495}\right)$, and $r p s 13\left(\mathrm{~A} / \mathrm{C}^{170}\right)$ were identified as unique to the alloplasmic line, and differentiate it from both parents. Our data shows that the ribosomal coding genes are the most variable when compared to the other mitochondrial protein coding genes. Three out of six SNPs observed between the (lo) durum and the Ae. longissima were found in the ribosomal protein coding genes rps2, rps4 and rps13 (Table 3).

Differences in nucleotide sequences between genomes results in changes in amino acid sequences and potentially function of proteins. Several of the observed differences (Table 3) also change the amino acid sequences. To try to predict whether the observed amino acid changes would result in altered activities, the amino acid sequences of the cox $3, \operatorname{rps} 13$, and $m t t B$ proteins were compared to other related monocots and Arabidopsis thaliana. All of the observed changes were found in

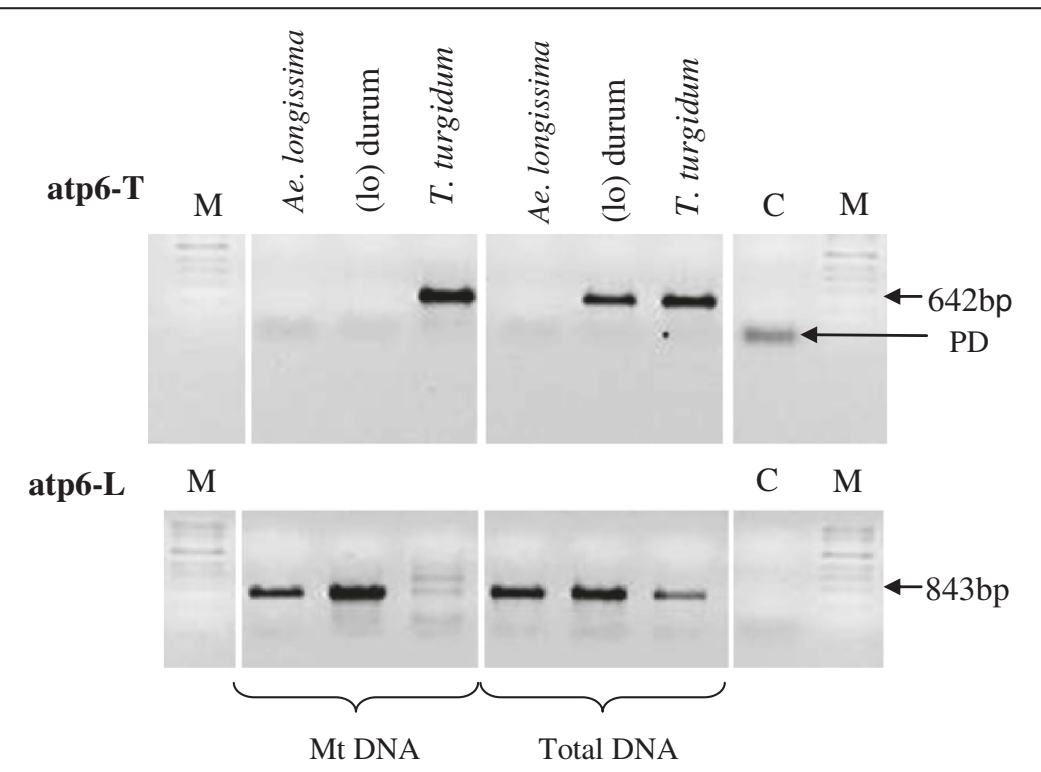

Figure 3 Differentiation of the atp6 alleles revealed by amplification using two sets of forward primers designed based on mitochondrial genome sequences (Additional file 3: Table S3). The atp6-T amplification of atp6 allele from the T. turgidum and atp6-L amplification of atp6 from the Aegilops longissima and the (lo) durum line. DNA was separated on a 1\% agarose gel. M indicates bp size marker, C indicates control PCR, PD - primers dimers. 
Table 2 Nucleotide variation(s) in ribosomal protein coding genes

\begin{tabular}{|c|c|c|c|c|c|}
\hline & & T. turgidum & Ae. longissima & (lo) durum & Amino acid change \\
\hline \multirow[t]{12}{*}{ Ribosomal proteins } & $\operatorname{rps} 1-1^{*}$ & + & - & - & - \\
\hline & rps $1-2$ & - & $C / A^{33}, C / T^{397}$ & $C / A^{33}, C / T^{397}$ & No change, $T / l$ \\
\hline & rps2-1 & + & + & - & $Y / F$ \\
\hline & rps $2-2$ & - & - & $A / T^{233}$ & \\
\hline & rps4-1 & + & - & - & - \\
\hline & rps $4-2$ & - & $G / T^{146}, T / G^{236}$ & - & $R / L, L / R$ \\
\hline & $r p s 4-3$ & - & - & $G / T^{146}, T / G=236, C / A^{495}$ & $R / L, L / R+$ no change \\
\hline & $\operatorname{rps} 13-1$ & + & - & - & - \\
\hline & $\operatorname{rps} 13-2$ & - & $\mathrm{A} / \mathrm{C}^{45}$ & - & No change \\
\hline & $\operatorname{rps} 13-3$ & - & - & $\mathrm{A} / \mathrm{C}^{45}, \mathbf{A} / \mathrm{C}^{170}$ & No change, E/A \\
\hline & rp/5-1 & + & - & - & - \\
\hline & $r p / 5-2$ & - & $\mathrm{G} / \mathrm{T}^{28}$ & $\mathrm{G} / \mathrm{T}^{28}$ & \\
\hline \multirow[t]{2}{*}{ tRNA } & His $t R N A-1$ & + & - & - & - \\
\hline & His $t R N A-2$ & - & $C / T^{10}, T / C^{22}$ & $C / T^{10}, T / C^{22}$ & Not applicable \\
\hline Variations $^{\&}$ & & 0 & 6 & 9 & \\
\hline
\end{tabular}

Arabic numbers indicate the SNP position relative to the start codon.

$+/-$ Indicates the presence/absence of gene allele in a particular genome.

${ }^{*}$ Gene with multiple alleles. Reported here are the most abundant alleles.

\&Summary of nucleotide variation observe only in genes with one known allele of that gene within species.

Listed are the nucleotide changes found in the (lo) durum, and the Ae. longissima with the T. turgidum as the reference sequence. The SNPs characteristic for the alloplasmic line are bold.

Table 3 Nucleotide variation(s) within the coding genes of the electron transport complexes

\begin{tabular}{|c|c|c|c|c|c|}
\hline & Gene & T. turgidum & Ae. longissima & (lo) durum & Amino acid change \\
\hline \multirow[t]{2}{*}{ Complex I } & nad3-1* & + & - & - & - \\
\hline & nad3-2 & - & $\mathrm{T} / \mathrm{C}^{185}$ & $\mathrm{~T} / \mathrm{C}^{185}$ & $\mathrm{~L} / \mathrm{P}$ \\
\hline \multirow[t]{3}{*}{ Complex IV } & $\cos 3-1$ & + & - & - & - \\
\hline & $\cos 3-2$ & - & $\mathrm{A} / \mathrm{C}^{157}, \mathrm{GA} / \mathrm{TC} \mathrm{C}^{687}$ & - & $\mathrm{I} / \mathrm{L}, \mathrm{QM} / \mathrm{HL}$ \\
\hline & $\cos 3-3$ & - & - & $A / C^{157}$ & $\mathrm{I} / \mathrm{L}$ \\
\hline \multirow[t]{8}{*}{ Complex V } & atp1-1 & + & - & - & - \\
\hline & $\operatorname{atp} 1-2$ & - & $\mathrm{A} / \mathrm{T}^{1431}$ & $\mathrm{~A} / T^{1431}$ & No change \\
\hline & $\operatorname{atp} 8-1-1^{*}$ & + & - & - & - \\
\hline & atp8-1-2 & - & $C / A^{239}$ & - & \\
\hline & atp8-1-3 & - & - & $C / T^{39}, A / G^{149}, G / A^{166}$ & \\
\hline & $\operatorname{atp} 8-11-1^{*}$ & + & - & - & - \\
\hline & atp8-11-2 & - & $C / A^{239}, G / A^{463}, T / C^{467}$ & - & \\
\hline & atp8-1I-3 & - & - & $G / A^{462}, T / C^{467}$ & \\
\hline \multirow[t]{2}{*}{ Other proteins } & $m t t B-1$ & + & + & - & - \\
\hline & $m t t B-2$ & - & - & $T / G^{41}$ & L/W \\
\hline Variations $^{\&}$ & & 0 & 4 & 3 & \\
\hline
\end{tabular}

Arabic numbers indicate the SNP position relative to the start codon.

$+/-$ Indicates the presence/absence of gene allele in a particular genome.

*Gene with multiple alleles. Reported here are only the most abundant alleles.

\& Summary of nucleotide variation observe only in genes with one know allele of that gene within species.

Listed are the nucleotide changes found in the (lo) durum, and the Ae. longissima with the $T$. turgidum as the reference sequence. The SNP's characteristic for each line are bold. 
other species with the exception of the $A / E^{57}$ change in the rps13 gene of the (lo) durum which was unique to that line (Figure 4).

\section{Variations in copy number of genes}

Some genes such as $c \mathrm{cmB}$ and $\mathrm{rpl5}$ (Figure 2) were missing in the (lo) durum mitochondrial genome. The $r p l 5$ gene is present in the Ae. longissima genome. There were also differences in the number of gene copies for instance atp 6 and atp 8 were present in two copies (alleles) in the assembled Ae. longissima mitochondrial genome but just one copy in the assemble (lo) durum genome. Three copies of rrn18 were identified in T. turgidum and in the (lo) durum genomes, while just one copy was present in the Ae. longissima. No polymorphism within these genes was identified among the species. Two copies of the rrn 26 gene were identified in the $T$. turgidum, two copies in the Ae. longissima (with one copy having the $\mathrm{T} / \mathrm{C}^{743} \mathrm{SNP}$ ), and one copy in the (lo) durum.

\section{SNPs between and within the chondriome of each line}

The existence of heteroplasmy was confirmed based on the existence of SNPs within chondriome of each line studied hereafter referred to as heteroplasmic SNPs (HSNPs). Within the chondriomes of the T. turgidum, the (lo) durum, and the Ae. longissima, 244, 218, and 344 HSNPs were identified, respectively (Additional file 7: Table S2). During the SNP search multiple regions of higher HSNP density (HSNP blocks) were evident compared to regions with only a single nucleotide change. These regions were unevenly distributed throughout the mitochondrial genomes. In the T. turgidum 22 HSNP blocks were identified containing 151 HSNPs, in the (lo) durum 15 blocks with 155 HSNPs (Figure 5) and in the Ae. longissima 14 regions, with 99 HSNPs in contig I and 13 regions, 147 HSNPs in contig II. No specific pattern of HSNP blocks was recognized. The number of HSNPs outside of these HSNP blocks were 93, 61, 98 in the T. turgidum, the (lo) durum and the Ae. longissima respectively (Additional file 7: Table S2).

A polymorphism search between the final consensus sequences of each genome was also performed. In total, 349 and 740 SNPs found comparing the (lo) durum line with the Ae. longissima and the T. turgidum respectively. There were also 731 SNPs between the Ae. longissima and the T. turgidum.

\section{ORF identification and comparison}

Previously, several ORFs (designated as 359, 240, 173 and 349) have been identified in the T. aestivum [7]. The sequenced species were checked for the presence and

\begin{tabular}{|c|c|c|c|c|c|}
\hline \multicolumn{6}{|l|}{$\operatorname{cox} 3$} \\
\hline & \multicolumn{3}{|c|}{$\begin{array}{ll}70 & 80\end{array}$} & 240 & 250 \\
\hline & \multicolumn{3}{|c|}{---------+----------+--} & $------+---\quad--$ & ----+- \\
\hline A. thaliana & \multicolumn{3}{|c|}{ SLGLIFILYTMFVWWRDVLRE } & IICGIRQYLG HL & TKEHHV \\
\hline Z. perennis & \multicolumn{3}{|c|}{ SLGLIFLLYTMFVWWRDVLRE } & IICGIRQYLG HL & TKEHHV \\
\hline O. sativa Indica & \multicolumn{3}{|c|}{ SLGLIFLLYTMFVWWRDVLRE } & IICGIRQYLG HL & TKEHHV \\
\hline Ae. longissima & \multicolumn{3}{|c|}{ SLGLIFLLYTMFVWWRDVLRE } & IICGIRQYLG HL & TKEHHV \\
\hline T. aestivum & \multicolumn{3}{|c|}{ SLGLIFILYTMFVWWRDVLRE } & IICGIRQYLG QM & TKEHHV \\
\hline T. turgidum & \multicolumn{3}{|c|}{ SLGLIFILYTMFVWWRDVLRE } & IICGIRQYLG QM & TKEHHV \\
\hline (lo) durum & \multicolumn{3}{|c|}{ SLGLIFLLYTMFVWWRDVLRE } & IICGIRQYLG QM & TKEHHV \\
\hline Consensus & \multicolumn{3}{|c|}{ SLGLIFILYTMFVWWRDVLRE } & IICGIRQYLG hl & TKEHHV \\
\hline \multirow[t]{2}{*}{ rps 13} & \multirow{2}{*}{\multicolumn{3}{|c|}{$m t t B$}} & \multirow[b]{2}{*}{10} & \multirow[b]{2}{*}{20} \\
\hline & & & & & \\
\hline Z. perennis & I & E QMIAQ & A. thaliana & NPSLLALNYLYISYE & $\mathbf{F}$ NFAS \\
\hline O. sativa Indica & I & E QMIAQ & Z. perennis & MPKMHLSFELLI--E & $W$ NFAP \\
\hline T. aestivum & I & E QMIAQ & O. sativa Indica & MPKMHLSFELLI--E & $W$ NFAP \\
\hline T. turgidum & I & E QMIAQ & T. aestivum & MPQIHFSFELLI--F & I NFAP \\
\hline Ae. longissima & I & E QMIAQ & T. turgidum & MPQIHFSFELLI--F & I NFAP \\
\hline (lo) durum & I & A QMIAQ & Ae. longissima & MPQIHFSFELLI--F & F I NFAP \\
\hline Consensus & I & e QMIAQ & (lo) durum & MPQIHFSFELLI--F & $\mathrm{E} W \mathrm{NFAP}$ \\
\hline & & & Consensus & mP..h.sfellI..e & e. N \\
\hline
\end{tabular}

Figure 4 Multi-alignment of protein sequences related to $\operatorname{cox} 3, \operatorname{rps} 13, \mathrm{mttB}$ genes from different species. Gray boxes indicate amino acid changes which are functionally important. Only fragment of genes are shown where polymorphism of interest was present. 


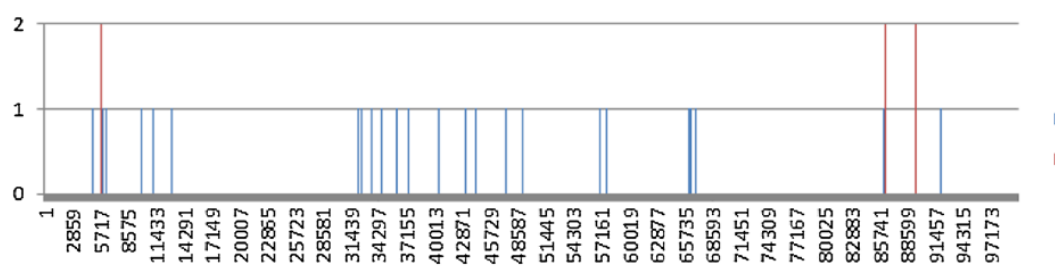

- HSNPs

- HSNP blocks

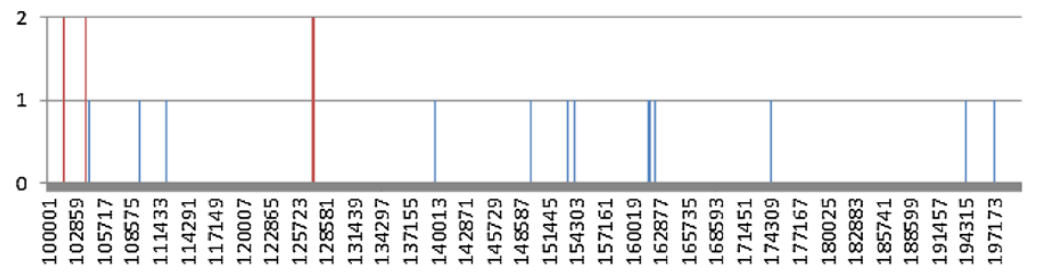

- HSNPs

- HSNP blocks

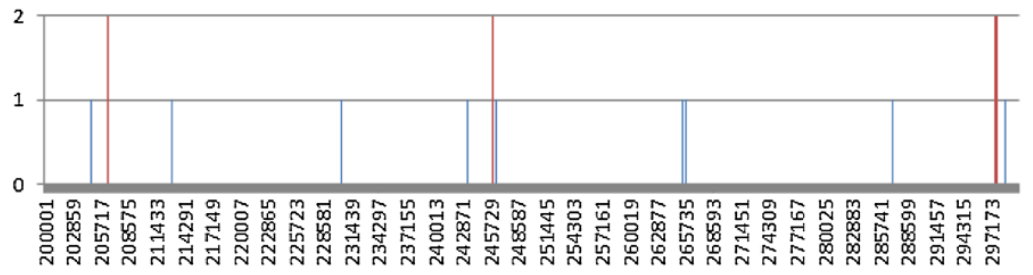

- HSNPS

- HSNP blocks

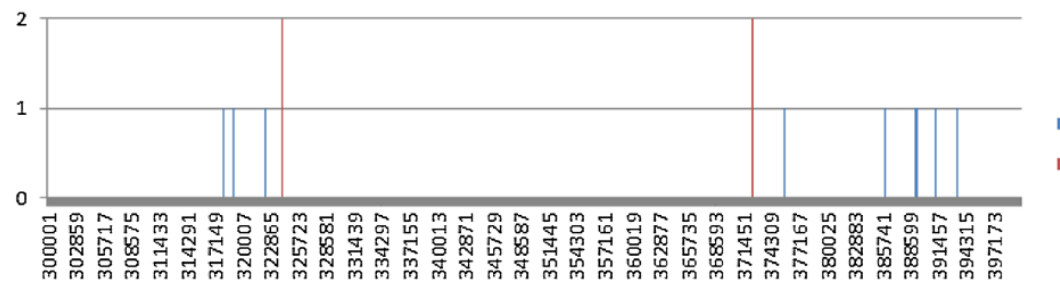

-HSNPs

-HSNP blocks

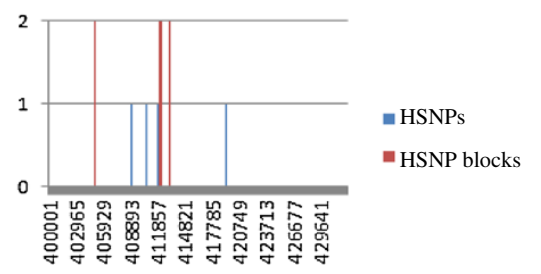

Figure 5 HSNP distribution across the (lo) durum mitochondrial genome. Blue lines indicates HSNP positions, red line indicate the position of HSNP blocks. We found 216 HSNPs in total, out of them 63 were HSNPs and 155 created 15 HSNP blocks. The overall HSNP density is 1HSNP/7,091 bp.

potential polymorphism in these ORFs. The orf173 and orf240 did not show any polymorphism among sequenced species. The orf349 in the alloplasmic line and the Ae. longissima carried a di-nucleotide difference of TT/AG ${ }^{68}$ when compared to the T. turgidum genome. The orf359 from the T. turgidum, which was identical to the T. aestivum, was not present in Ae. longissima. Only a portion of that gene, from 73 bp to 1,080 bp was found in the (lo) durum. This ORF is significantly different in the alloplasmic line with 48 SNPs, three di-nucleotide changes, one tri-nucleotide change, and one triplet nucleotide insertion in regards to the T. turgidum's copy of the ORF. This appears to be the most polymorphic region found in the sequenced genomes when compared to the $T$. turgidum (Additional file 8: Figure S5).
The T. turgidum, the (lo) durum, and the Ae. longissima genomes have 184 ORFs, 191 ORFs, and 163 ORFs with sizes larger than $300 \mathrm{bp}$, respectively. These ORFs consist of 81,978 bp (18.1\%), 90,237 bp (20.8\%) and $78,651 \mathrm{bp}$ $(19.7 \%)$ of the total genome size in each species, respectively. The alloplasmic line has the largest number of ORFs compared to its parents and the highest percentage of total ORF sequence per genome. To determine if there are species specific ORFs, a comparison of the ORFs was performed. There were 27 ORFs in the (lo) durum which are not present in the T. turgidum and the Ae. longissima, 15 ORFs present only in the Ae. longissima, and 26 ORFs only in the T. turgidum.

The ORFs unique to the alloplasmic line are further described in Table 4. Based on a Mega BLAST search 


\begin{tabular}{|c|c|c|c|c|}
\hline \multirow[b]{2}{*}{ ORF\# } & \multicolumn{2}{|c|}{$\begin{array}{l}\text { Alloplasmic, CMS T. aestivum } \\
\text { line (GU985444.1) }\end{array}$} & \multicolumn{2}{|c|}{$\begin{array}{l}\text { Normal, T. aestivum } \\
\text { (EU534409) }\end{array}$} \\
\hline & Coverage (\%) & Identity (\%) & Coverage (\%) & Identity (\%) \\
\hline 14 & 14 & 100 & 14 & 97 \\
\hline $26^{*}$ & 100 & 97 & 100 & 97 \\
\hline 63 & 100 & 100 & - & - \\
\hline 65 & 100 & 99 & - & - \\
\hline 84 & - & - & 31 & 100 \\
\hline 112 & 100 & 99 & - & - \\
\hline 113 & 85 & 99 & 91 & 99 \\
\hline 114 & 100 & 100 & 10 & 98 \\
\hline $122^{*}$ & 100 & 97 & 100 & 98 \\
\hline 138 & 22 & 100 & - & - \\
\hline 146 & 100 & 98 & 66 & 98 \\
\hline
\end{tabular}

*These two ORFs are not present in the final T. turgidum assembly. - indicates absence of ORF in that line.

against the NCBI database ORFs $0,1,3,50,61,74,97$, 108, 159, 177 hit no similar sequences, possibly making them specific to this line. The ORFs 63, 65, 112 from the alloplasmic durum line are also present in the male sterile, alloplasmic line of T. aestivum [36] with $99 \%$ or more similarity (Table 4). The ORFs 122 and 146 are fully present in the alloplasmic $T$. aestivum [36], but only a portion of these ORFs exist in normal common wheat. Additionally, in male fertile and male sterile lines of the $T$. aestivum, orf14, and orf113 are different from that found in the alloplasmic durum. Based on its composition, orf113 (396 bp) from the (lo) durum is composed of fragments of other known and functional mitochondrial genes rps2, cox 1, nad4 exon-2, and rps19-p (Additional file 9: Figure S6).

\section{Discussion}

The chondriome is known to carry different types of mitochondrial genomes and showing polymorphism within each cell and tissue type [21]. Most reports on heteroplasmy in plants are based on sequencing of a few genes or ORFs [18,22,37]. The next generation sequencing method used in this study allowed deep sequencing with a range of $61-102 x$ coverage in the mitochondrial genome of all three lines. This provided a clearer picture of heteroplasmy within each mtDNA (mtDNA hereafter will refer to different types of mitochondrial genomes or mitotypes presented in heteroplasmic condition in a plant). Heteroplasmy was observed in inter-genic space as well as genic space within each genome. Most mtDNA sequencing in wheat to date has been based on BAC or large cosmid library construction $[7,36]$. This may make genome assembly easier due to the lower complexity of the data, but it also can limit the understanding of heteroplasmy and substoichiometric changes of the mitotypes in the chondriome.

This study provides for the first time a detailed analyses of an alloplasmic line of wheat in comparison to its two euplasmic nuclear and cytoplasmic donor lines. Analysis of the mitochondrial genome of an alloplasmic wheat with the Ae. kotschyi cytoplasm reported by Liu and his colleagues [36] lacked the sequence information of the genome from the euplasmic Ae. kotschyi maternal line for a better comparison. Reference assembly identified, several gaps in the mitochondrial genomes of the $T$. turgidum, the Ae. longissima and the (lo) durum as compared with that of the T. aestivum (Figure 1). Genome rearrangements and structural changes were evident using the de novo assembly of the mitochondrial genomes of the three lines (Figure 2). Mitochondrial genome of the alloplasmic line was not only distinct from the T. turgidum but also different from its maternal parent the Ae. longissima. Differences in gene order have not only been reported between different species of the same family, because of gene shuffling [7], but also among different ecotypes of a single species such as Arabidopsis [37]. Different genome structures have been observed comparing euplasmic lines with the CMS lines in maize [9], rice [13] and wheat [36]. Structural changes between the three genomes were expected, but the degree of these changes, which occurred in less than 50 years for the (lo) durum line, is quite significant. The rearrangements observed between the (lo) durum and the Ae. longissima mitochondrial genomes were greater than that observed for the T. turgidum and the T. aestivum, which are separated by 10,000 years of evolution [38]. The Ae. longissima mitochondrial genome has undergone a drastic structural change possibly as a result of introducing a new nuclear genome and production of a live alloplasmic line [39].

In alloplasmic conditions, incompatibility between the encoded gene products from nucleus and mitochondria could lead to altered mitochondrial function. The enzymes of the inner mitochondrial membrane which contain subunits encoded from both mitochondria and nuclear genomes may not be compatible and less functional in the newly formed alloplasmic line [40]. This pressure in addition to possible changes in recombination, due to improper function of nuclear gene(s) such as MSH1 and RECA3 [41] that control recombination in the mitochondrial genome, can lead to high frequency of heteroplasmy. The substoichiometric changes in favor of mitotypes that survive better in the new condition will accelerate evolution. This accelerated evolution of newly formed mitotypes can lead to multiple types different from the maternal mitochondrial genome in organization and genetic information, as found here and in other species $[9,13]$. Therefore, in the alloplasmic CMS lines, not only a larger 
number of newly formed mitotypes exist, but also the stoichiometric shift changes the predominant mitotype from the maternal type to the one best suited to the new condition [20].

Multiple synteny blocks were observed between different lines possibly indicating sites of recombination (Figure 2). Studies on wheat mitochondrial gene expression indicated that nad6 and nad1 (exon d) are cotranscribed [42]. Both genes were found to be present in Block II, despite the high structural differences observed. Therefore, the co-existence of genes in the same block may be related to their functional association. At least 10 large repeated sequences exist in the wheat mitochondrial genome making it possible to have multiple sub-genomic circles in a cell. Multiple genome rearrangements, likely caused by recombination in mitochondrial repeated sequences, would result in the conserved coding regions often flanked by different sequences [40]. The co-existence of different mitotypes in a cell after these rearrangements may have hampered the production of a contiguous assembly of the whole wheat mitochondrial genome. Although reference assembly with the $T$. aestivum mitochondrial genome was possible for the T. turgi$d u m$, it was problematic for the other two lines. De novo assembly in these situations provided a better and more complete picture of the genome and its organization. The de novo assembly of mitochondrial genome was a challenge in our study due to the multipartite nature and rearrangements through recombination. The same difficulty was also faced by other groups using next generation sequencing of mitochondrial genome [13]. The de novo assembly using MIRA program followed by manual editing resulted in one contig of $\sim 432 \mathrm{~kb}$ and two contigs with combined length of $\sim 399 \mathrm{~kb}$ for the (lo) durum and the Ae. longissima, respectively. This emphasizes the necessity for developing more bioinformatics tools that are specific for mitochondrial genome analysis.

All previously characterized genes in the $T$. aestivum mitochondrial genome were present in the alloplasmic line and its parents. Despite conservation in gene content, multiple genes showed considerable sequence differences. The alloplasmic durum and the Ae. longissima line shared the same sequence variation in a number of genes such as atp6-1, nad6, rps19-p, cob and cox2 exon2 when compared to the T. turgidum. The atp 6 subunit of $\mathrm{F}_{0} \mathrm{~F}_{1}-\mathrm{ATP}$ synthase is considered to be a mitochondrial encoded gene. Early studies recognized the chimeric structure of atp6 in Triticum species [43]. Later, it was found that the presence of those chimeric versions were associated with cytoplasmic male sterility in rice, where proper RNA editing of altered apt6 could restore male fertility [44]. The same differences in atp6-1, nad6, rps19-p, $c o b$ and cox 2 exon 2 identified in this study have been reported by Liu et al. [36] in an alloplasmic line of $T$. aestivum with the cytoplasm of Ae. kotschyi. These appear to be the common differences between the Triticum and Aegilops genera rather than being due to the CMS condition as reported by Kawaura [22] for atp6.

To confirm the allelic differences of atp 6 between the (lo) durum and its parental lines, a complimentary PCR was performed with specific primers for each allele after genome sequencing (Figure 3). It seems the alloplasmic and its euplasmic maintainer have both atp6-T and atp6-L versions of the gene. However, atp6-T version appears to be only present in the (lo) durum nucleus rather than in mitochondria. The same situation seems valid for the presence of atp6-L in the T. turgidum nucleus. Recently it has been shown that two versions of atp 6 are present in the Ae. crassa, T. aestivum cv. Chinese Spring and the alloplasmic line of Chinese spring with the Ae. crassa cytoplasm [22]. The atp6-CR (crassa) version in Chinese Spring and atp6-AE (aestivum) version in the Ae. crassa were present in less than $10 \%$ of the mitochondrial pool in the cell. However, the frequency of atp6-AE was $30 \%$ in the alloplasmic line possibly due to paternal leakage. There was no obvious amplification for atp6-T in the (lo) durum or the Ae. longissima mtDNA and atp6-L in the T. turgidum mtDNA (Figure 3). Therefore, presence of a nuclear copy of both genes is likely.

Three different alleles of nad9 were identified in this study. The allele found in the alloplasmic line is more similar to that of the paternal T. turgidum line than the Ae. longissima. This provides another evidence of paternal leakage during the creation of the alloplasmic line. Paternal leakage and its contribution to heteroplasmy has been indicated by numerous studies [19,22,45-47]. In wheat paternal leakage was investigated in detail in the alloplasmic hexaploid wheat having Ae. crassa cytoplasm [22]. It seems the proportion of paternal genes in the alloplasmic line increases by each backcrossing with the paternal line and then remains at a constant level [22]. The sequence of nad9 in the (lo) durum has similarities to both parents. Therefore, this copy of nad9 not only shows paternal leakage but also suggests that a recombination between the maternal and paternal mitochondrial genomes may have occurred. Since the Ae. longissima copy of the gene is absent in the (lo) durum, paternal leakage was either high for this gene and/or the nucleus of the T. turgidum selected in favor of the recombinant version which was similar to its own. It is known that nuclear genes determine the stoichiometry of alternative mitotypes [47]. Therefore, the second reason is most likely to be valid.

Two genes, $r p l 5$ and $c c m B$ were missing in the final assembly of the (lo) durum. The $r p l 5$ gene encodes a ribosomal protein, responsible for rRNA maturation and formation of the $60 \mathrm{~S}$ ribosomal subunits. Its function could be critical to the survival of the alloplasmic line. 
Both $r p l 5$ and $c c m B$ genes were present in the raw assembly data but not included in the final assembly. In a recent study on sequencing the mitochondrial genome of a CMS line of $T$. aestivum, the lack of $r p l 5$ gene was associated with the CMS phenotype [36]. The lack of this gene in the final assemblies of the (lo) durum in our study and the (Ae. kotschyi) alloplasmic line [36] may be related to the proportion of mitochondrial DNA carrying that gene by means of substoichiometric shifting [48]. It is possible that the $r p l 5$ gene exists in a mitotype which is in a much smaller proportion compared to the major mitotype in the cell.

Besides major changes discussed, a nucleotide polymorphism search was performed within known mitochondrial genes in the sequenced species. Out of six SNPs observed between the (lo) durum and the Ae. longissima, three were in ribosomal protein coding genes rps 2 , rps 4 and rps13. Nucleotide variation within ribosomal genes was also observed in the alloplasmic line of $T$. aestivum, where among other, differences in rps 2 , and rps4 were recognized [36]. This indicates that ribosomal genes are the possible "hot spots" for mutation in alloplasmic lines. Since ribosomal proteins are responsible for protein expression, these differences may be important to our understanding of CMS phenotype in plants. These findings suggest the possibility of creating potential SNP based markers to investigate other cytoplasm in alloplasmic lines of wheat. The functional effect of nucleotide variation in cox3, rps 13 , and $m t t B$ gene was evaluated in comparison to A. thaliana, Zea perennis, $T$. aestivum and Oryza sativa sub. Indica (Figure 4). Amino acid variations found in these genes are common among various plant species except for the change in rps13 leading to an amino acid change unique to the alloplasmic line. This data supports the hypothesis of accelerated evolutionary changes in alloplasmic lines observed here and in another study [49].

Nucleotide polymorphism could be detected within each chondriome and categorized as single HSNPs and HSNP blocks. The HSNP blocks within each chondriome is an indicator of heteroplasmy in each genome and could possibly be used to investigate the proportion of particular mitotype in the genome. Overall mitochondrial genome polymorphism comparison between chondriome of each line showed an expected result that the alloplasmic line is closer to the Ae. longissima than to the T. turgidum. In the alloplasmic durum line, one particular region of DNA, designated as orf359 [7], showed the highest level of polymorphism compared to other regions of the genome. Gene content and order showed that orf359 does not exist in the cytoplasm donor line, but was completely conserved (sequence and position) among the T. aestivum and the T. turgidum genomes. Existence of orf359 in the alloplasmic durum line is additional evidence for paternal leakage, although it was highly mutated. Since the (lo) durum line has been developed through a complicated backcrossing scheme including the (lo) T. aestivum cv. Selkirk and the T. timopheevii [39], the impact of these changes may have influenced the new ORF composition. Sequencing of the T. timopheevii mitochondrial genome can provide a better insight to these observations.

Several open reading frames specific to the alloplasmic line were detected, implying that alloplasmic condition can lead to creation of new ORFs. These new ORFs can contribute to CMS and other characteristic phenotypes in the (lo) durum line. Interestingly, ORFs 63, 65, 112 from the alloplasmic durum line were also observed in the alloplasmic hexaploid wheat containing the Ae. kotchyi cytoplasm [36]. The occurrence of these ORFs might be related to the alloplasmic condition for they were not present in the maternal lines. As both alloplasmic lines having these ORFs are CMS, it is possible that their existence are associated with the CMS condition. The most characteristic ORF recognized in this study was chimeric orf113 (Additional file 9: Figure S6) composed entirely of four fragments of other mitochondrial genes, including rps2, cox1, nad4-2, and rps19-p. Expression of a new chimeric ORF "orf72" in wild cabbage has been found to be related to the CMS phenotype [50]. This ORF contained parts of atp 9 and expressed in CMS line, but not in the euplasmic line. It was also found that expression of orf224/atp6 chimeric gene is correlated with CMS trait in Brassica napus [51].

\section{Conclusions}

Next generation sequencing technologies are powerful tools to study the heteroplasmy and substoichiometric changes of mitochondrial genomes in chondriome of plants, especially alloplasmic lines. Several heteroplasmic regions were observed within genes and also intergenic regions. The amount of structural changes in the (lo) durum lines was considerably higher than its cytoplasm donor. The rearrangements and nucleotide changes in the mitochondrial genome of the alloplasmic line that occurred in less than half a century was greater than the changes observed between mitochondrial genome of the T. turgidum and the T. aestivum which remained almost intact for 100 centuries of evolution. Evidence of paternal leakage was also observed by analyzing nad9 and orf359 among all three lines. The significance of changes in the genes received from the paternal donor emphasizes that other mechanisms such as recombination, mutation, and substoichiometric shifts are active in the alloplasmic condition. Together the newly formed ORFs, differences in gene sequences and copy numbers, heteroplasmy and substoichiometric changes demonstrate the potential of the alloplasmic condition to accelerate evolution towards forming new mitochondrial genomes. Inducing changes in 
the chondriome and selection for the best mitotypes that fit the growing conditions would definitely broaden the paths for crop improvement in the future.

\section{Methods}

Plant material

Three lines from Triticum-Aegilops genera, T. turgidum ssp. turgidum conv. durum (Desf.) selection 56-1, Ae. longissima S.\&M. (G759), and the alloplasmic durum line [(lo) durum] were used for sequencing of the mitochondrial genomes. The (lo) durum wheat is a male sterile alloplasmic line where the cytoplasm is derived from Ae. longissima and the nucleus from T. turgidum carrying a nuclear species cytoplasm-specific gene from $T$. timopheevii $\left(s c s^{t i}\right)$ that is necessary for proper compatibility [39]. This line is maintained by crossing to euplasmic durum [(d) - - ] line 56-1, with no copy of the scs gene. Seeds produced are half plump and viable carrying the $s c s^{t i}$ locus, and half are shriveled and inviable. All the plants studied, were grown in the greenhouse and kept in dark for 2 weeks prior to mitochondrial isolation.

\section{Mitochondrial DNA isolation and amplification}

Mitochondria isolation was conducted according to the protocol developed by Triboush et al. [35] with minor modifications. Before mitochondrial isolation leaf tissues were rinsed with $4^{\circ} \mathrm{C}$ distilled water and transferred to the cold room $\left(4^{\circ} \mathrm{C}\right)$. All subsequent steps of procedure were performed in the cold room to prevent organelle degradation. Tissue homogenization was performed using the hand blender. Homogenized tissue was filtered through nylon woven mesh with 50 microns opening (Nitex). Samples were centrifuged to isolate intact mitochondria. Nuclear and chloroplast DNA contaminations were removed from the sample by DNaseI (Sigma-Aldrich Co, St. Louis, USA) treatment at $37^{\circ} \mathrm{C}$ for 30 minutes. Mitochondrial DNA was isolated immediately after stopping DNaseI activity using Mammalian Genomic DNA Miniprep Kit (Sigma-Aldrich Co, St. Louis, USA). To check for the proportion of probable nuclear and chloroplastic DNA contamination a quantitative real time PCR assay, using (7900HT Fast Real-Time PCR System, Applied Biosystems ${ }^{\mathrm{Tm}}$ ) was performed. Three genome specific primers were applied for QRT-PCR reactions using TaKaRa SYBR ${ }^{\circ}$ Premix Ex Taq ${ }^{\text {Tm }}$ II (Perfect Real Time, Takara Bio, Madison, USA). Gene specific primers for chloroplast (gene psb60), mitochondrial (gene nad3) and nuclear genomes (retrojunction nuclear marker) were used to test purity (Additional file 3: Table S3). No amplification of nuclear DNA was detected in any sample of mitochondrial DNA while amplification occurred using total DNA as a positive control (data not presented). Mitochondrial DNA was amplified following the manufacturer's protocol for the Illustra ${ }^{\text {tux }}$ GenomiPhi $^{\text {in }}$ V2 DNA
Amplification Kit (GE Healthcare, Fairfield, USA). After amplification, aliqouts of DNA were separated on 1\% agarose gels for quality and quantity confirmation. Amplified DNA was acetone precipitated [52] and quantified using the Nanodrop spectrophotometer (Thermo Fisher Scientific Inc, USA). Approximately $20 \mu \mathrm{g}$ of each mtDNA sample, dissolved in water was used for sequencing.

\section{Mitochondrial genome sequencing}

Shot-gun, one-end sequencing by 454 Pyrosequencing $^{\mathrm{m}}$ was performed at USDA-ARS, Albany, CA, USA. An additional mtDNA concentration measurement was done using Quant-iT ${ }^{\mathrm{mix}}$ PicoGreen $^{\circ}$ dsDNA Assay Kit (Invitro$\operatorname{gen}^{\mathrm{Tw}}$, USA). The mitochondrial DNA was fragmented by nebulization and fragments from 500 to $700 \mathrm{bp}$ were selected for sequencing. Sequencing was done using the 454 GS FLX Titanium sequencer, with GS Titanium General Library Prep Kit, GS Titanium SV emPCR kit, GS Titanium LV emPCR kit, GS Titanium sequence kit XLR70 and GS Titanium PicoTiterPlate kit 70x75 according to manufacturer protocols.

\section{Mitochondrial genome assembly}

Genome assembly was completed using the software MIRA3 [53] on a PC/UNIX platform. Reference assembly for each genome was performed with the T. aestivum (Genbank, NC_007579.1) mitochondrial genome as a backbone and Tripsacum dactyloides (Genbank, DQ984517) was used as negative control for assembly. The de novo assemblies were also performed for mitochondrial genome of each line. To assemble the (lo) durum genome, de novo and reference assembly were used at the same time, with the T. aestivum genome as reference, to partially guide the assembly within common regions of both genomes. The GAP4 software [54] was used to manually edit/join contigs obtained directly from the assembly software to create the final consensus sequences. Joining was performed only for contigs with an overlap greater than $100 \mathrm{bp}$ and less than $1 \%$ dissimilarity in the overlapping region. Artemis: DNA Sequence Viewer and Annotation Tool software was used to create images of the mitochondrial genome assembly [55]. Visualization of the reference genome assembly was done using Tablet software [56]. For processing pictures IrfanView 4 (Irfan Skiljan, Wiener Neustadt, Austria) was used.

To perform de novo genome assembly using one end sequencing data we relied only on the nucleotide sequence of the read. Current assembly software programs were not able to complete assembly of the mitochondrial genome properly with one end data without extensive manual trimming, joining and large contig editing. Additionally due to the presence of long and short repeated sequences (present multiple times in mitochondrial genomes) and the high level of heteroplasmy, a single contig 
could not be created for each genome using only the algorithm implemented in the software. To overcome these difficulties, assembly was performed by extension of each contig separately against all reads to create overlaps and to find sequence spanning contigs.

\section{Gene finding, ORF prediction and genome annotation}

Gene sequences and names were annotated based on the T. aestivum mitochondrial genome [35]. The NCBI database was searched for plant mitochondrial genome sequences. An open reading frame search was performed using NCBI ORF Finder according to standard translation table. The ORF's were named arbitrarily starting from 0 for sequences being $300 \mathrm{bp}$ or longer. The ORF comparison between the three mitochondrial genomes was performed and unique ORF's were reported for each species with comparison to the other two genomes using the BLAST algorithm. Only ORFs which were $95 \%$ or less of the query size were considered as unique and these ORFs were reported and described.

\section{Mitochondrial genome polymorphism}

The assembled sequences for each genome were used as references for SNP detection. The raw reads from the same line were mapped against the reference sequence for that line. The raw assembly files from GAP4 software [54] were used to search for polymorphism for each sequenced position. Only regions of the genome with at least a 10x threshold of genome coverage were used for SNP search. A SNP was reported only when the number of different nucleotides in the same position was observed in more than $10 \%$ of the reads and sequence coverage of that region was at least 10X. With this criterion only $0.3 \%(1,283 \mathrm{bp})$ to $1 \%(3,962 \mathrm{bp})$ of the genome were not considered in the analysis (Additional file 7: Table S2). A SNP search between mitochondrial genomes was performed by using the BLAST search due to the high number of rearrangement between genomes. An identity of $95 \%$ was used as the cut off for finding similar regions through BLAST search, and in that region SNPs were detected as described before. An error rate (false positive) for the SNP search was established comparing 17,046 bp of gene space (which are: atp1, atp9, rps13, cox3, matR, rps1, ccmFN, cob, rpl16, rps3, ccmFC, orf359, nad4, orf240, $\operatorname{ccm} B, \operatorname{atp} 4, \operatorname{nad} 2, \operatorname{orf173}, \operatorname{nad} 9 \operatorname{orf349}, \operatorname{rps} 2)$ between sequenced species and the $T$. aestivum reference. Only nucleotide changes were considered in the SNP analysis. Nucleotide insertion/deletion events were not reported.

\section{Confirmation of sequence assemblies and atp 6 gene structure}

The sequence of the atp6-1 gene in all three sequenced species was confirmed by Sanger sequencing of the complete gene, using the mtDNA and total genomic DNA. Additionally, the presence/absence and sequence of atp6-1 was confirmed by PCR using atp6LO, atp6TU as forward primers in combination with a common reverse primer (atp6TU-R) designed in the core region of the gene (Additional file 3: Table S3). PCR with specific primers was performed to confirm proper contig structure and structural differences between the $T$. turgidum and the (lo) durum genomes. The primer design was made using OLIGO Primer Analysis Software v.7 [57] following by Primer-BLAST [58].

Final genome assembly was used to explain the overall structural differences between the genomes. Assignment of gene positions in each genome, allowed the creation of gene synteny maps showing only gene relationships between mitochondrial genomes in sequenced species. Double ACT v2 (Health Protection Agency) together with ACT software (Artemis Comparison Tool) from Sanger Institute was used to demonstrate syntenic differences and gene positions across sequenced mitochondrial genomes.

\section{Additional files}

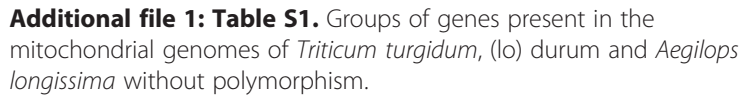

Additional file 2: Figure S1. The sequence of atp6 gene including the conserved regions of mitochondrial genome surrounding both alleles. Region in blue represents a pre-sequence of the atp6 gene, starting from ATG codon. Region in green represent the conserved region and gray bars shows polymorphism found within core region of the gene.

Additional file 3: Table S3. The PCR primers for DNA quantification and atp6 sequence confirmation. These primers were used to establish level of chloroplast and nuclear DNA contamination in the mitochondrial DNA samples and to differentiate between alleles of the atp6 gene.

Additional file 4: Figure S2. The nad9 nucleotide sequence comparison between (lo) durum and the parental lines. Three SNP's were recognized (light gray boxes) in comparison to the Triticum turgidum, one of them (dark gray box) was found only in the (lo) durum line. The four-nucleotide deletion in the Ae. longissimum creates a STOP codon at the base 157. An additional di-nucleotide change (CA/TG ${ }^{134-135}$ ) in the (lo) durum is indicated by the orange box.

Additional file 5: Figure S3. The nad6 nucleotide sequence comparison between the (lo) durum and the parental lines. Three SNPS were recognized and two di-nucleotide changes (light gray boxes) in comparison to the T. turgidum. The highly polymorphic region starts at position 703 as indicated by the arrow.

Additional file 6: Figure S4. The rps19-p nucleotide sequence comparison between the (lo) durum and the parental lines. In the T. turgidum there is a nine nucleotide deletion in rps19-p when compared to the (lo) durum and the Ae. longissimum which share the same allele.

Additional file 7: Table S2. Number of heteroplasmic single nucleotide polymorphisms (HSNPs) and clusters of polymorphism found within each of the three sequenced mitochondrial genomes.

Additional file 8: Figure S5. The orf359 nucleotide sequence comparison between the (lo) durum and the parental lines. The sequence of orf359 found in the alloplasmic line was highly polymorphic when compared to the T. turgidum gene. We identified 48 SNP's, three di-nucleotide changes, one tri-nucleotide change, and one three nucleotide insertion. The Ae. longissima sequence assembly does not have a copy of orf359. 
Additional file 9: Figure S6. Structure of orf113 specific to the alloplasmic durum line. Database search showed similarity to rps2, cox 1 nad4-2, rps 19- $p$ mitochondrial genes. Shown are the relative fragment size and location of each gene found in the ORF.

\section{Competing interests}

The authors declare that they have no competing interests.

\section{Authors' contributions}

SM, and SFK designed the research; AKN performed the research; AKN, LAN, and $\mathrm{AS}$ analyzed the data; $\mathrm{YG}, \mathrm{NH}$ conducted the 454 pyrosequencing ${ }^{\mathrm{TM}}$; $\mathrm{FG}$, AKN and PMAK drafted and edited the manuscript, FG and SFK managed the project. All authors read and approved the final draft of the manuscript.

\section{Acknowledgements}

The authors wish to thank Drs. Justin Faris and David Horvath for careful review of the manuscript and valuable comments. The authors also wish to thank Dr. Gerard Lazo, Justin Hegstad and Allen Peckrul for their technical support throughout the research. This work was supported by funding from the United States Army Research Office grant No. W911NF-08-1-0319 to S.F. Kianian as the PI.

\section{Sequence accession numbers (GenBank)}

Refer to following GenBank accession number for sequences in this document:

T. longissimum - KJ078648

T. turgidum L. var durum acc. 56-1 - KJ078649

(lo) durum - KJ078650

\section{Author details}

'Department of Plant Sciences, North Dakota State University, Fargo, ND 58108, USA. ²Department of Plant Pathology, University of Minnesota, St. Paul, MN 55108, USA. ${ }^{3}$ Computer Information Systems Department, The University of Jordan, Amman, Jordan. ${ }^{4}$ USDA-ARS, Western Regional Research Center, Albany, CA 94710, USA. ${ }^{5}$ Department of Plant Pathology, North Dakota State University, Fargo, ND 58108, USA. ${ }^{6}$ Cereal Disease Laboratory, USDA-ARS, Minneapolis, MN 55108, USA.

Received: 27 February 2013 Accepted: 15 January 2014

Published: 25 January 2014

\section{References}

1. Miquel J, Economos AC, Fleming J, Johnson JE Jr: Mitochondrial role in cell aging. Exp Gerontol 1980, 15(6):575-591

2. Ryan MT, Hoogenraad NJ: Mitochondrial-nuclear communications. Annu Rev Biochem 2007, 76:701-722.

3. Dyall SD, Brown MT, Johnson PJ: Ancient invasions: from endosymbionts to organelles. Science 2004, 304(5668):253-257.

4. Woodson JD, Chory J: Coordination of gene expression between organellar and nuclear genomes. Nat Rev Genet 2008, 9(5):383-395.

5. Alverson AJ, Wei X, Rice DW, Stern DB, Barry K, Palmer JD: Insights into the evolution of mitochondrial genome size from complete sequences of Citrullus lanatus and Cucurbita pepo (Cucurbitaceae). Mol Biol Evol 2010, 27(6):1436-1448.

6. Burger G, Gray MW, Lang BF: Mitochondrial genomes: anything goes. Trends Genet 2003, 19(12):709-716.

7. Ogihara Y, Yamazaki Y, Murai K, Kanno A, Terachi T, Shiina T, Miyashita N, Nasuda S, Nakamura C, Mori N, Takumi S, Murata M, Futo S, Tsunewaki K: Structural dynamics of cereal mitochondrial genomes as revealed by complete nucleotide sequencing of the wheat mitochondrial genome. Nucleic Acids Res 2005, 33(19):6235-6250.

8. Notsu Y, Masood S, Nishikawa T, Kubo N, Akiduki G, Nakazono M, Hirai A Kadowaki K: The complete sequence of the rice (Oryza sativa L.) mitochondrial genome: frequent DNA sequence acquisition and loss during the evolution of flowering plants. Mol Genet Genomics 2002, 268(4):434-445.

9. Allen JO, Fauron CM, Minx P, Roark L, Oddiraju S, Lin GN, Meyer L, Sun $H_{\text {, }}$ Kim K, Wang C, Du F, Xu D, Gibson M, Cifrese J, Clifton SW, Newton KJ: Comparisons among two fertile and three male-sterile mitochondrial genomes of maize. Genetics 2007, 177(2):1173-1192.
10. Clifton SW, Minx P, Fauron CM, Gibson M, Allen JO, Sun H, Thompson M, Barbazuk WB, Kanuganti S, Tayloe C, Meyer L, Wilson RK, Newton KJ: Sequence and comparative analysis of the maize NB mitochondrial genome. Plant Physiol 2004, 136(3):3486-3503.

11. Handa $\mathrm{H}$ : The complete nucleotide sequence and RNA editing content of the mitochondrial genome of rapeseed (Brassica napus L.): comparative analysis of the mitochondrial genomes of rapeseed and Arabidopsis thaliana. Nucleic Acids Res 2003, 31(20):5907-5916.

12. Unseld M, Marienfeld JR, Brandt $P$, Brennicke $A$ : The mitochondrial genome of Arabidopsis thaliana contains 57 genes in 366,924 nucleotides. Nat Genet 1997, 15(1):57-61.

13. Bentolila S, Stefanov S: A reevaluation of rice mitochondrial evolution based on the complete sequence of male-fertile and male-sterile mitochondrial genomes. Plant Physiol 2012, 158(2):996-1017.

14. Ma P-F, Guo Z-H, Li D-Z: Rapid sequencing of the bamboo mitochondrial genome using illumina technology and parallel episodic evolution of organelle genomes in grasses. PLoS One 2012, 7(1):e30297.

15. Zhang T, Hu S, Zhang G, Pan L, Zhang X, Al-Mssallem IS, Yu J: The organelle genomes of Hassawi Rice (Oryza sativa L.) and its hybrid in Saudi Arabia: genome variation, rearrangement, and origins. PLOS One 2012, 7(7):e42041.

16. Woloszynska M, Trojanowski D: Counting mtDNA molecules in Phaseolus vulgaris: sublimons are constantly produced by recombination via short repeats and undergo rigorous selection during substoichiometric shifting. Plant Mol Biol 2009, 70(5):511-521.

17. Li M, Schonberg A, Schaefer M, Schroeder R, Nasidze I, Stoneking M: Detecting heteroplasmy from high-throughput sequencing of complete human mitochondrial DNA genomes. Am J Hum Genet 2010, 87(2):237-249.

18. Hattori N, Kitagawa K, Takumi S, Nakamura C: Mitochondrial DNA heteroplasmy in wheat, Aegilops and their nucleus-cytoplasm hybrids. Genetics 2002, 160(4):1619-1630.

19. Kmiec B, Woloszynska M, Janska H: Heteroplasmy as a common state of mitochondrial genetic information in plants and animals. Curr Genet 2006, 50(3):149-159.

20. Woloszynska M: Heteroplasmy and stoichiometric complexity of plant mitochondrial genomes-though this be madness, yet there's method in't. J Exp Bot 2010, 61(3):657-671

21. Arrieta-Montiel M, Lyznik A, Woloszynska M, Janska H, Tohme J, Mackenzie S: Tracing evolutionary and developmental implications of mitochondrial stoichiometric shifting in the common bean. Genetics 2001, 158(2):851-864.

22. Kawaura K, Saeki A, Masumura T, Morita S, Ogihara Y: Heteroplasmy and expression of mitochondrial genes in alloplasmic and euplasmic wheat. Genes Genet Syst 2011, 86(4):249-255.

23. Rand DM, Haney RA, Fry AJ: Cytonuclear coevolution: the genomics of cooperation. Trends Ecol Evol 2004, 19(12):645-653.

24. Hanson MR: Plant mitochondrial mutations and male-sterility. Annu Rev Genet 1991, 25:461-486.

25. Levings CS, Vasil IK: The molecular biology of plant mitochondria. Dordrecht; Boston: Kluwer Academic Publishers; 1995.

26. Linke $B$, Borner $\mathrm{T}$ : Mitochondrial effects on flower and pollen development. Mitochondrion 2005, 5(6):389-402.

27. Levings CS: Thoughts on cytoplasmic male-sterility in Cms-T Maize. Plant Cell 1993, 5(10):1285-1290.

28. Lilly JW, Bartoszewski G, Malepszy S, Havey MJ: A major deletion in the cucumber mitochondrial genome sorts with the MSC phenotype. Curr Genet 2001, 40(2):144-151.

29. Lilly JW, Havey MJ: Small, repetitive DNAs contribute significantly to the expanded mitochondrial genome of cucumber. Genetics 2001, 159(1):317-328.

30. Ogihara Y, Kurihara Y, Futami K, Tsuji K, Murai K: Photoperiod-sensitive cytoplasmic male sterility in wheat: nuclear-mitochondrial incompatibility results in differential processing of the mitochondrial $<\mathrm{i}>$ orf $25</ \mathrm{i}>$ gene. Curr Genet 1999, 36(6):354-362.

31. Tsunewaki K, Wang GZ, Matsuoka Y: Plasmon analysis of Triticum (wheat) and Aegilops. 1. Production of alloplasmic common wheats and their fertilities. Genes Gen Syst 1996, 71(5):293-311.

32. Tsunewaki K, Wang GZ, Matsuoka Y: Plasmon analysis of Triticum (wheat) and Aegilops. 2. Characterization and classification of 47 plasmons based on their effects on common wheat phenotype. Genes Genet Syst 2002, 77(6):409-427. 
33. Liu CG, Wu YW, Hou H, Zhang C, Zhang Y, Mclntosh RA: Value and utilization of alloplasmic common wheats with Aegilops crassa cytoplasm. Plant Breed 2002, 121(5):407-410

34. Wu Y, Zhang C, Liu C, Shuxin R, Yan Z: Breeding technology of alloplasmic wheat. Sci China C Life Sci 1998, 41(5):449-458.

35. Triboush SO, Danilenko NG, Davydenko OG: A method for isolation of chloroplast DNA and mitochondrial DNA from sunflower. Plant Mol Biol Rep 1998, 16(2):183-189.

36. Liu HT, Cui P, Zhan K, Lin Q, Zhuo G, Guo X, Ding F, Yang W, Liu D, Hu S, $Y u$ J, Zhang A: Comparative analysis of mitochondrial genomes between a wheat K-type cytoplasmic male sterility (CMS) line and its maintainer line. BMC Genomics 2011, 12:163.

37. Ullrich $H$, Lattig K, Brennicke A, Knoop V: Mitochondrial DNA variations and nuclear RFLPs reflect different genetic similarities among 23 Arabidopsis thaliana ecotypes. Plant Mol Biol 1997, 33(1):37-45.

38. Dubcovsky J, Dvorak J: Genome plasticity a key factor in the success of polyploid wheat under domestication. Science 2007, 316(5833):1862-1866.

39. Maan SS: Transfer of a Species Cytoplasm Specific (Scs) Gene from Triticum.timopheevi to Triticum.turgidum. Genome 1992, 35(2):238-243.

40. Nair CKK: Mitochondrial genome organization and cytoplasmic malesterility in plants. J Biosci 1993, 18(3):407-422

41. Shedge V, Arrieta-Montiel M, Christensen AC, Mackenzie SA: Plant mitochondrial recombination surveillance requires unusual RecA and MutS homologs. Plant Cell 2007, 19(4):1251-1264.

42. Haouazine N, Takvorian A, Jubier M-F, Michel F, Lejeune B: The nad6 gene and the exon $\mathrm{d}$ of nad 1 are co-transcribed in wheat mitochondria. Curr Genet 1993, 24(6):533-538.

43. Bonen $L$, Bird S: Sequence analysis of the wheat mitochondrial atp6 gene reveals a fused upstream reading frame and markedly divergent $\mathrm{N}$ termini among plant ATP6 proteins. Gene 1988, 73(1):47-56.

44. Iwabuchi M, Kyozuka J, Shimamoto K: Processing followed by complete editing of an altered mitochondrial Atp6 RNA restores fertility of cytoplasmic male sterile rice. Embo J 1993, 12(4):1437-1446.

45. Bentley KE, Mandel JR, McCauley DE: Paternal leakage and heteroplasmy of mitochondrial genomes in Silene vulgaris: evidence from experimental crosses. Genetics 2010, 185(3):961-968.

46. Wagner DB, Dong J, Carlson MR, Yanchuk AD: Paternal leakage of mitochondrial DNA in Pinus. Theor App/ Genet 1991, 82(4):510-514.

47. Yang X, Griffiths AJF: Male transmission of linear plasmids and mitochondrial-DNA in the fungus neurospora. Genetics 1993 134(4):1055-1062.

48. Chen J, Guan R, Chang S, Du T, Zhang H, Xing H: Substoichiometrically different mitotypes co-exist in mitochondrial genomes of Brassica napus L. PLoS One 2011, 6(3):e17662.

49. Darracq A, Varre JS, Marechal-Drouard L, Courseaux A, Castric V, SaumitouLaprade P, Oztas S, Lenoble P, Vacherie B, Barbe V, Touzet P: Structural and content diversity of mitochondrial genome in beet: a comparative genomic analysis. Genome Biol Evol 2011, 3:723-736.

50. Shinada T, Kikuchi Y, Fujimoto R, Kishitani S: An alloplasmic male-sterile line of Brassica oleracea harboring the mitochondria from Diplotaxis muralis expresses a novel chimeric open reading frame, orf72. Plant Cell Physiol 2006, 47(4):549-553.

51. Wang H-M, Ketela T, Keller W, Gleddie S, Brown G: Genetic correlation of the orf224/atp6 gene region with Polima CMS in Brassica somatic hybrids. Plant Mol Biol 1995, 27(4):801-807.

52. Sambrook J, Fritsch EF, Maniatis T: Molecular cloning: a laboratory manual. NY: Cold Spring Harbor Laboratory Press; 1989.

53. Chevreux B, Pfisterer T, Drescher B, Driesel AJ, Müller WEG, Wetter T, Suhai S: Using the miraEST assembler for reliable and automated mRNA transcript assembly and SNP detection in sequenced ESTs. Genome Res 2004, 14:1147-1159.

54. Bonfield JK, Smith KF, Staden RA: A new DNA sequence assembly program. Nucleic Acids Res 1995, 23:4992-4999.

55. Carver T, Berriman M, Tivey A, Patel C, Böhme U, Barrell BG, Parkhill J, Rajandream MA: Artemis and ACT: viewing, annotating and comparing sequences stored in a relational database. Bioinformatics 2008, 24(23):2672-2676.

56. Milne I, Bayer M, Cardle L, Shaw P, Stephen G, Wright F, Marshall D: Tablet - next generation sequence assembly visualization. Bioinformatics 2010, 26(3):401-402
57. Rychlik W: OLIGO 7 primer analysis software. Methods Mol Biol 2007, 402:35-60.

58. Rozen S, Skaletsky HJ: Primer3 On the WWW for general users and for biologist programmers. In Bioinformatics methods and protocols: methods in molecular biology. Edited by Krewetz S, Misener S. Totowa, NJ: Humana Press; 2000.

doi:10.1186/1471-2164-15-67

Cite this article as: Noyszewski et al:: Accelerated evolution of the mitochondrial genome in an alloplasmic line of durum wheat. BMC Genomics 2014 15:67.

\section{Submit your next manuscript to BioMed Central and take full advantage of:}

- Convenient online submission

- Thorough peer review

- No space constraints or color figure charges

- Immediate publication on acceptance

- Inclusion in PubMed, CAS, Scopus and Google Scholar

- Research which is freely available for redistribution 